\title{
Relation between right ventricular enlargement, QRS duration, and right ventricular function in patients with tetralogy of Fallot and pulmonary regurgitation after surgical repair
}

\author{
M Y Abd El Rahman, H Abdul-Khaliq, M Vogel, V Alexi-Meskishvili, M Gutberlet, \\ P E Lange
}

\begin{abstract}
Objective-In patients with repaired tetralogy of Fallot, to examine (1) a possible relation between right ventricular enlargement and QRS prolongation, and (2) the effect of right ventricular enlargement caused by pulmonary regurgitation on the right ventricular ejection fraction, evaluated by three dimensional echocardiography, and global function, evaluated by the myocardial performance index.

Design and patients-40 patients with repaired tetralogy were studied. Right ventricular volumes were derived from three dimensional echocardiographic data after this method had been validated by comparison with magnetic resonance imaging in 21 patients. Ejection fraction was calculated from end diastolic and end systolic volumes. The Doppler derived myocardial performance index was measured in all patients. Measured data were correlated with QRS duration.

Setting-Tertiary cardiac centre for congenital heart disease.

Results-There was good agreement between three dimensional echocardiographic and magnetic resonance assessment of right ventricular volumes and ejection fraction. The $\mathrm{z}$ score of the right ventricular end diastolic volume and ejection fraction of all patients was 1.35 and -4.15 , respectively. Patients with severe pulmonary regurgitation had a lower right ventricular ejection fraction $(\mathrm{p}<0.01)$ and an increased myocardial performance index $(\mathrm{p}<0.01)$ compared with patients with mild to moderate pulmonary regurgitation. The correlation between ejection fraction and right ventricular end diastolic volume was $r=-0.35(\mathrm{p}<0.05)$. The mean (SD) QRS duration was 131.89 (25.69) $\mathrm{ms}$, range 80-180 ms. The correlation between QRS duration and right ventricular end diastolic volume was $r=0.6(\mathrm{p}<0.01)$.

Conclusions-There is a correlation between the right ventricular size obtained by three dimensional echocardiography and QRS duration on the surface ECG, indicating mechanoelectrical interaction. The severity of pulmonary regurgitation has a negative influence on right ventricular ejection fraction and combined systolic and diastolic global function, as assessed by myocardial performance.

(Heart 2000;84:416-420)
\end{abstract}

Keywords: tetralogy of Fallot; pulmonary regurgitation; right ventricular enlargement; QRS prolongation

\section{Department of \\ Congenital Heart \\ Disease, Deutsches \\ Herzzentrum Berlin, \\ Augustenburger Platz \\ 1, 13353 Berlin, \\ Germany \\ M Y Abd El Rahman \\ H Abdul-Khaliq \\ $M$ Vogel \\ P E Lange}

Department of

Cardiac Surgery,

Deutsches

Herzzentrum Berlin

V Alexi-Meskishvili

Department of Radiology, Charité Berlin,

Augustenburger Platz, Berlin, Germany

M Gutberlet

Correspondence to: Dr Abdul-Khaliq

Abdul-Khaliq@dhzb.de

Accepted 12 July 2000
In recent years, several studies have emphasised the importance of mechanoelectrical interaction in patients with surgically corrected tetralogy of Fallot. ${ }^{1-3}$ From these studies we have learnt that a duration of the QRS complex on the surface ECG of more than $180 \mathrm{~ms}$ is associated with an increased risk of malignant ventricular dysrhythmias, and that the pulmonary regurgitation which is prevalent after transannular patch repair may predispose to arrhythmias and a poor long term outcome. ${ }^{4-6}$ Thus far, no attempt has been made to examine possible correlations between the abnormal QRS prolongation, right ventricular function, and right ventricular end diastolic volume. Novel techniques of volumetry such as magnetic resonance imaging ${ }^{7}$ and three dimensional echocardiography - which overcome the limitations of other imaging techniques for the assessment of right ventricular volumes-have recently become available, ${ }^{89}$ as has a new Doppler derived index of combined systolic and diastolic right ventricular performance. ${ }^{10}{ }^{11}$ Our purpose in this study was first, to compare data from right ventricular volumetry obtained by three dimensional echocardiography with clinical data including the ECG, and second, to examine a possible relation between the severity of pulmonary regurgitation and end diastolic right ventricular volume, ejection fraction, and combined systolic and diastolic function, assessed by right ventricular myocardial performance index in patients with repaired tetralogy of Fallot.

\section{Methods}

PATIENT POPULATION

The population studied consisted of 40 patients who had had corrective surgery for tetralogy of Fallot, selected from among 181 patients regularly followed in our outpatient department. These 40 patients were selected on the basis that they were living in the vicinity of Berlin, came to regular outpatient visits at least once a year, had no obvious cardiac symptoms, and had good transthoracic windows for echocardiographic examination. Their mean (SD) age at the time of study was 
14.3 (9.5) years (range 3-44 years). Their age at complete repair was 4.7 (7.2) years (range $0.25-43$ years). The follow up period was 9.5 (6.0) years (range 1-25 years). During surgical repair the right ventricular outflow tract was primarily reconstructed by a valved homograft in 19 patients $(47.5 \%)$ or by right ventricular outflow tract patch in $16(40 \%)$. In five $(12.5 \%)$ a second operation had been performed because of severe right ventricular outflow tract obstruction or pulmonary regurgitation, and in all of these a homograft was implanted.

RIGHT VENTRICULAR VOLUME MEASUREMENTS

For assessment of end diastolic and end systolic volumes a transthoracic three dimensional echocardiographic study was performed with rotational scanning. ${ }^{8}$ Digital data from the GE Vingmed System V (GE Vingmed, Horten, Norway) were stored on an off-line personal computer and analysed with dedicated software provided by GE-Vingmed, which is not yet commercially available. The algorithms are similar to previously used software provided by Tomtec (Tomtec, Munich, Germany). Along the longest axis of the right ventricle, the area of $1 \mathrm{~mm}$ thick slices is manually outlined and then multiplied by the slice thickness to obtain slice volumes; the individual slice volumes are then summed to obtain the whole ventricular volume. Although this method had previously been validated in vitro and in vivo, ${ }^{812} 13$ we performed a magnetic resonance imaging study within 24 hours of the three dimensional echocardiographic study in 21 of the 40 patients to validate the new software and assess whether three dimensional echocardiography can provide valid data in abnormally dilated right ventricles. For magnetic resonance imaging a 1.5 Tesla Philips instrument (Philips, Eindhoven, Netherlands) was used and volumes calculated using a previously published technique. ${ }^{8}$ Published normal values of right ventricular volume assessed by magnetic resonance imaging were used as the reference values with which the right ventricular volumes were compared. ${ }^{14}$

ECHOCARDIOGRAPHY AND DOPPLER STUDIES

All patients were examined using a $3.5 \mathrm{MHz}$ transducer interfaced with a Vingmed system $\mathrm{V}$ ultrasound system (GE-Vingmed). Transthoracic imaging was performed in the left lateral decubitus position. Initially, routine diagnostic imaging was performed, including colour flow mapping and continuous wave Doppler. Pulsed Doppler flow across the tricuspid and pulmonary valve was assessed with simultaneous ECG recordings in each patient. The myocardial performance index was assessed (fig 1) by measurement of time interval between closure and reopening of the tricuspid valve (a value) in the apical four chamber view, while the ejection time ( $b$ value) was measured in the parasternal short axis view. The right ventricular myocardial performance index was then compared with published normal values (mean (2 SD)). ${ }^{11}$

The degree of pulmonary regurgitation (mild to moderate, severe) was judged by two

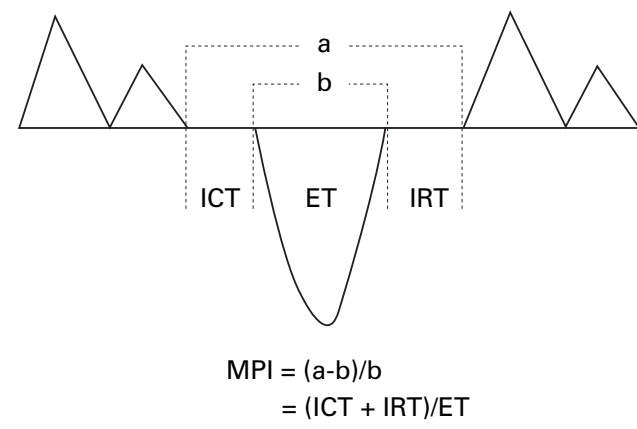

Figure 1 Illustration of the myocardial performance index (MPI).

experienced investigators by the width and length of the regurgitant jet in the right ventricle on colour Doppler echocardiography and by the velocity and pattern of regurgitant flow in the right ventricular outflow tract and pulmonary artery on pulsed Doppler echocardiography. ${ }^{15}$ Multiple subcostal or parasternal views were examined to determine the duration of pulmonary regurgitant jet.

\section{ELECTROCARDIOGRAM}

All patients had a 12 lead surface ECG performed using a Siemens recorder (Siemens, Erlangen, Germany) at a speed of $25 \mathrm{~mm} / \mathrm{s}$, and $1 \mathrm{mV} / \mathrm{cm}$ standardisation. The maximum QRS duration in any lead was measured from the first to the last sharp vector crossing the isoelectric line. Three patients who had pacemakers because of complete heart block were excluded from analysis of the ECG data.

STATISTICAL METHODS

Assessment of differences in the means of the measured variables in the patient groups was generally done by applying the non-parametric Mann-Whitney $U$ test for two unpaired samples. Limits for agreement were calculated according to Bland and Altman. ${ }^{16} \mathrm{~A}$ z score was calculated to compare end diastolic right ventricular volumes and ejection fraction with published normal values. ${ }^{14}$

\section{Results}

ASSESSMENT OF RIGHT VENTRICULAR VOLUMES

We were able to acquire good quality echocardiographic images in all patients. Calculation of right ventricular volume in end diastole or end systole took 20-30 minutes, depending on the right ventricular size, which determined the number of slices where the area had to be manually outlined. Accordingly, the time to obtain a calculated value for right ventricular ejection fraction was 40-60 minutes. Magnetic resonance imaging took 15 minutes (range 12-19 minutes) and calculation of volumes took 45 minutes (range 33-58 minutes).

The limits for agreement between end diastolic volume measurements by the two methods were -42.5 to $+69.4 \mathrm{ml}$ and the correlation curve had an $r$ value of 0.95 . Limits for agreement for end systolic volumes were -32.9 to $+51.1 \mathrm{ml}$ and the correlation curve had an $r$ value of 0.93 . Thirty five patients $(87.5 \%)$ had mild to moderate pulmonary regurgitation and five $(12.5 \%)$ had severe 

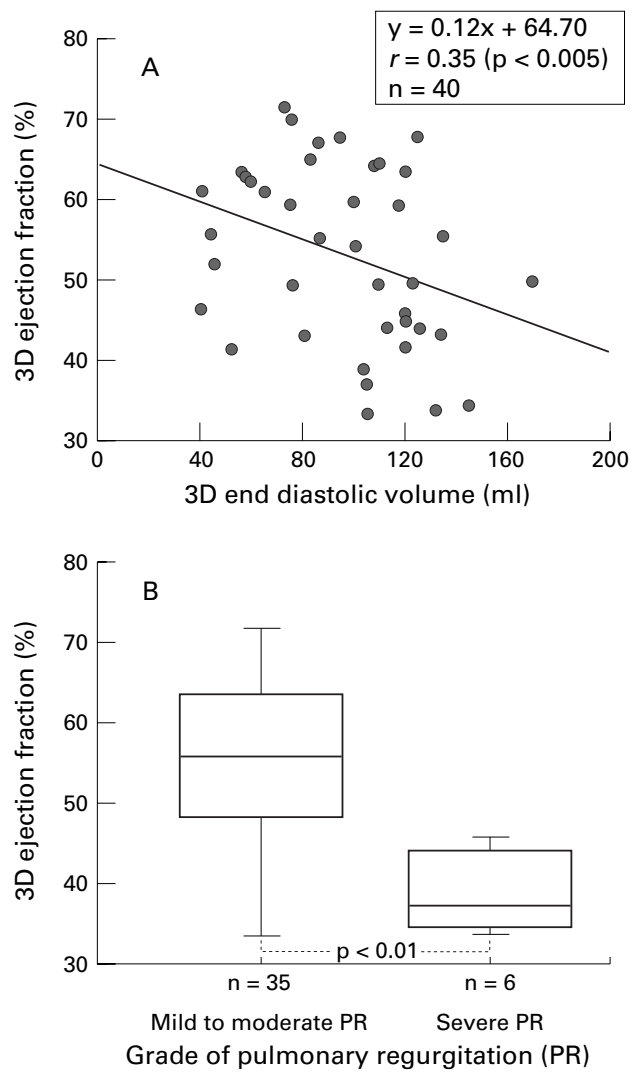

Figure 2 Right ventricular systolic dysfunction was observed following corrective surgery of tetralogy of Fallot, especially in patients with extreme right ventricular volume overload $(A)$ caused by severe pulmonary regurgitation (B).

pulmonary regurgitation. For comparison with Doppler and electrocardiographic data, only measurements obtained from three dimensional echocardiography were used.

The mean (SD) right ventricular end diastolic and end systolic volumes corrected to basal surface area were $80.2(19.6) \mathrm{ml} / \mathrm{m}$ (range $36.8-129.8 \mathrm{ml} / \mathrm{m}$ ) and 37.6 (13.5) $\mathrm{ml} / \mathrm{m}$ (range $13.4-73.6 \mathrm{ml} / \mathrm{m}$ ), respectively. The $\mathrm{z}$ score of the comparison between the corrected right ventricular end diastolic volume in all patients and the published normal values was 1.35. The right ventricular ejection fraction calculated from end diastolic and end systolic volumes was $53.4 \quad(11.0) \%$ (range 33.5$71.7 \%)$. The $\mathrm{z}$ score of the comparison between the ejection fraction in all patients and published normal values was -4.2 . Patients with severe pulmonary regurgitation (fig 2A) had a lower right ventricular ejection fraction than patients with mild to moderate pulmonary regurgitation $(\mathrm{p}<0.01)$. There was a negative correlation (fig $2 \mathrm{~B}$, fig 3 ) between the right ventricular ejection fraction and right ventricular end diastolic volume $(r=-0.35, \mathrm{p}<0.05)$, as well as the right ventricular end systolic volume $(r=-0.82, \mathrm{p}<0.01)$.

All patients had a right bundle branch block with a QRS duration of 131.9 (19.6) ms (range $80-180 \mathrm{~ms}$ ). A significant correlation was found between the QRS duration and the absolute right ventricular end diastolic volume $(r=061, \mathrm{p}<0.01)$ (fig 4A) and end systolic volume $(r=0.52, \mathrm{p}<0.01)$ (fig $4 \mathrm{~B})$. In

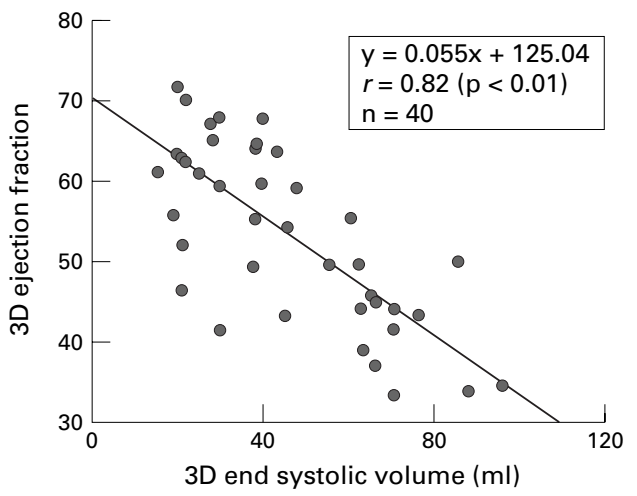

Figure 3 The known close relation between end systolic volume and ejection fraction can also be shown for right ventricular volumes determined by three dimensional echocardiography.
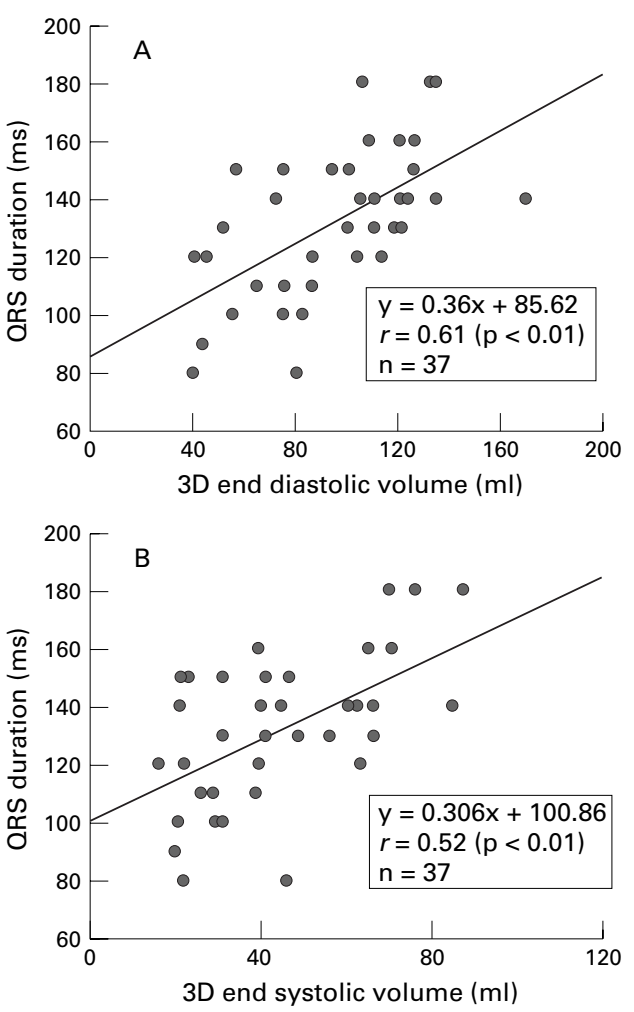

Figure 4 Right ventricular volume overload secondary to pulmonary regurgitation prolongs the QRS duration on the surface ECG.

addition, the QRS duration correlated significantly with age $(r=0.43, \mathrm{p}<0.01)$ as well as with the follow up period $(r=0.34, \mathrm{p}<0.05)$. No significant correlation was found between QRS duration and gradient across the right ventricular outflow tract.

RIGHT VENTRICULAR MYOCARDIAL PERFORMANCE INDEX

The myocardial performance index was 0.24 (0.18) (range 0.03-0.87). Twenty seven patients $(67.5 \%)$ had values below normal range, and six patients $(15 \%)$ had values above the normal range. Patients with severe pulmonary regurgitation (fig 5) had an increased index compared with patients with mild to moderate pulmonary regurgitation $(\mathrm{p}<0.01)$. The myocardial performance index was not 


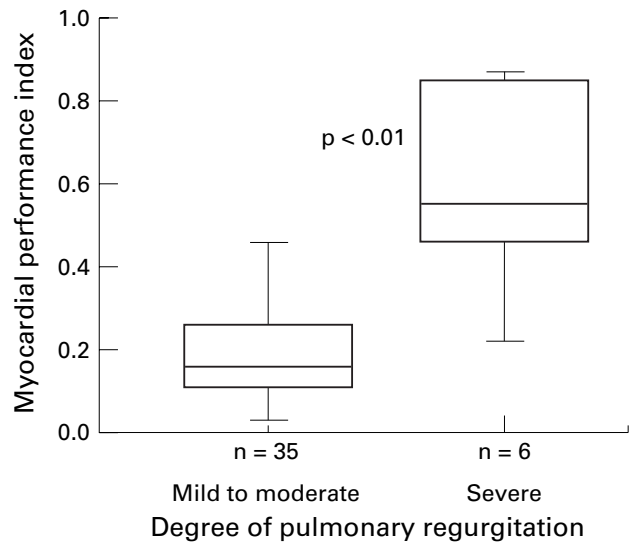

Figure 5 The myocardial performance index was increased in patients with severe pulmonary regurgitation following corrective surgery of tetralogy of Fallot, indicating impaired global function.

correlated with the duration of the QRS complex or with right ventricular size.

\section{Discussion}

THE MECHANOELECTRICAL INTERACTION

The pathogenesis of sustained ventricular tachycardia, thought to account for the majority of cases of sudden unexpected death after repair of the tetralogy of Fallot, remains unclear. $^{1-3}$ An association has been reported between ventricular enlargement secondary to pulmonary regurgitation and a prolonged QRS duration on the surface ECG as a predictor of ventricular arrhythmias. ${ }^{1}$ However, that study was based on the assumption that an increased cardiothoracic ratio on the plain chest $x$ ray predominantly reflected right ventricular size. Residual shunts at ventricular level, tricuspid regurgitation, left ventricular dilatation in chronic tachycardia, as well as the presence of pulmonary regurgitation may all result in an increased cardiothoracic ratio on the chest $x$ ray. In addition, it is still unclear whether mechanical events alone cause this electrical abnormality. By applying the newly available three dimensional echocardiography technique for measuring right ventricular volumes, we can confirm the hypothesis of a mechanoelectrical interaction. However, the correlation between right ventricular end diastolic or end systolic volumes and the duration of the QRS complex was rather weak, suggesting that additional factors, in particular the age and duration of follow up, ${ }^{1}$ may play a role. In our study the follow up period was shorter than in previous studies, ${ }^{117}$ which had reported an increase in the duration of the QRS complex with age. The low incidence of patients (four of 40) with a QRS duration $\geqslant 180 \mathrm{~ms}$ may be a reflection of the shorter follow up period in our patients.

EFFECT OF PULMONARY REGURGITATION ON THE RIGHT VENTRICULAR PERFORMANCE

A possible deleterious effect of pulmonary regurgitation on right ventricular function had been suggested in previous studies. ${ }^{18-20}$ In comparison with published normal values, the right ventricular end diastolic volume in $\mathrm{ml} / \mathrm{m}$ in our patients was significantly increased (z score $1.35)$ and the right ventricular ejection fraction significantly decreased ( $\mathrm{z}$ score -4.2 ). Such alterations were more common in patients with severe pulmonary regurgitation. Thus our data confirm previous studies suggesting a negative influence of pulmonary regurgitation on right ventricular systolic function and attributing this to an abnormally enlarged right ventricle. $^{21} 22$ Recently, the right ventricular myocardial performance index has been used as an additional non-invasive tool to assess right ventricular function in patients with an abnormally shaped right ventricle. ${ }^{10} 11$ This reflects the isovolumic contraction and relaxation activities of the ventricle in relation to the ejection time. However, it does not distinguish between altered systolic or diastolic function. The global effect of pressure overload on the right ventricle assessed by this index has been reported. ${ }^{10} \mathrm{~A}$ higher than normal index in those patients was indicative of reduced global ventricular function. In our study, patients with severe pulmonary regurgitation had a raised index indicating altered global function in severe volume overload.

The absence of a significant correlation between the right ventricular myocardial performance index and right ventricular end diastolic volume, as well as with the QRS duration, thus supports previous studies which have suggested that the index may not be affected by ventricular size or conduction delay. ${ }^{10}{ }^{11}$ As the abnormal right ventricular myocardial performance index present in $68 \%$ of our patients is unlikely to be caused by increased right ventricular volumes or conduction delay, it is speculated that the abnormal index may reflect changes in myocardial muscle mass and structure. ${ }^{23}$ Further studies that assess the degree of myocardial hypertrophy, and especially the presence and severity of fibrosis, are required to confirm this speculation.

LIMITATIONS OF THE STUDY

As three dimensional echocardiography when applied transthoracically ${ }^{8}$ has its limitations, we introduced a selection bias in this study in that we only examined patients with adequate transthoracic echocardiographic windows. While the method of volume assessment by either three dimensional echocardiography or magnetic resonance imaging is accurate, it is still time consuming and requires expensive equipment, limiting its more widespread use.

Doppler assessment of the severity of pulmonary regurgitation may not be the ideal method for quantification but because of technical limitations we did not use magnetic resonance flow studies, which may well become the gold standard for assessment of pulmonary regurgitation. ${ }^{7}$ To limit the inherent problems of Doppler echocardiography in assessing the severity of pulmonary regurgitation in the present study, two experienced cardiologists have determined the extent of pulmonary regurgitation in order to differentiate patients with severe pulmonary regurgitation from those with mild to moderate regurgitation. 
CONCLUSIONS

From our data we conclude that prolongation of the QRS duration is not related to mechanical factors alone, as the correlation between the right ventricular size and the QRS complex is rather weak. Secondly we conclude that severe pulmonary regurgitation negatively influences right ventricular systolic function as well as combined right ventricular systolic and diastolic function assessed by the myocardial performance index.

MAER was supported by the DAAD. We are indebted to Dr Mohnhaupt from the department of biometrics and medical statistics of the Humboldt University Berlin for help with the statistical evaluation of the data.

1 Gatzoulis MA, Till JA, Somerville J, et al. Mechanoelectrical interaction in tetralogy of Fallot. QRS prolongation relates to right ventricular size and predicts malignan ventricular arrhythmias and sudden death. Circulation 1995;92:231-7.

2 Cullen S, Celermajer DS, Franklin RC, et al. Prognostic significance of ventricular arrhythmia after repair of tetralogy of Fallot: a 12-year prospective study. $\mathcal{F} \mathrm{Am}$ Coll Cardiol 1994;23:1151-5.

3 Giroud D, Zimmermann M, Adamec R, et al. Ventricular late potentials and spontaneous ventricular arrhythmias after surgical repair of tetralogy of Fallot: do they have prognostic value? Br Heart 7 1994;72:580-3

4 Arsan S, Yorgancioglu C, Pasaoglu I, et al. The influence of pulmonary insufficiency on ventricular function following pulmonary insufficiency on ventricular function following correction of Fallot's tetralogy: evaluation using radionu-
clide ventriculography and clinical findings. Turk $\mathcal{F}$ Pediatr 1993;35:323-31.

5 Fogel MA, Rychik J. Right ventricular function in congenital heart disease: pressure and volume overload lesions. Prog Cardiovasc Dis 1998;40:343-56.

6 Norgard G, Gatzoulis MA, Moraes F, et al. Relationship between type of outflow tract repair and postoperative ventricular diastolic physiology in tetralogy of Fallot. Implications for long-term outcome. Circulation 1996;94:3276-80

7 Rebergen SA, Chin JG, Ottenkamp J, et al. Pulmonary regurgitation in the late postoperative follow-up of tetralogy of Fallot. Volumetric quantitation by nuclear magnetic resonance velocity mapping. Circulation 1993;88: 2257-66.

8 Vogel M, Gutberlet M, Dittrich S, et al. Comparison of transthoracic three dimensional echocardiography with magnetic resonance imaging in the assessment of right venmagnetic resonance imaging in the assessment of righ

9 Papavassiliou DP, Parks WJ, Hopkins KL, et al. Threedimensional echocardiographic measurement of right ven- tricular volume in children with congenital heart disease validated by magnetic resonance imaging. I $\mathrm{Am}$ Soc Echocardiogr 1998;11:770-7.

10 Tei C, Dujardin KS, Hodge DO, et al. Doppler echocardiographic index for assessment of global right ventricular function. $\mathcal{F}$ Am Soc Echocardiogr 1996;9:838-47.

11 Eidem BW, Tei C, O'Leary PW, et al. Nongeometric quantitative assessment of right and left ventricular function: Myocardial performance index in normal children and patients with Ebstein anomaly. F $\mathrm{Am}$ Soc Echocardiogr 1998;11:849-56.

12 Vogel $M$, White PA, Redington $A N$. In vitro validation of right ventricular volume measurement by three dimensional echocardiography. Br Heart $\mathcal{F}$ 1995;74:460-3.

13 Jiang L, Siu SC, Handschumacher MD, et al. Threedimensional echocardiography. In vivo validation for right ventricular volume and function. Circulation 1994;89: 2342-50.

14 Helbing WA, Rebergen SA, Maliepaard C, et al. Quantification of right ventricular function with magnetic resonance maging in children with normal hearts and with congenital heart disease. Am Heart 7 1995;130:828-37.

15 Hatle L, Angelsen B. Pulsed and continuous wave Doppler in diagnosis and assessment of various heart lesions. In: Hatle L, Angelson B, eds. Doppler ultasound in cardiology, 2nd ed. Philadelphia: Lea and Febiger, 1985:162-70.

16 Bland JM, Altman DG. Statistical methods for assessing agreement between two methods of clinical measurement. Lancet 1986;i:307-10.

17 Gatzoulis M, Till J, Redington A. Depolarizationrepolarization inhomogeneity after repair of tetralogy of Fallot. The substrate for malignant tachycardia. Circulation 1997;95:401-4.

18 Helbing WA, Niezen RA, Le Cessie S, et al. Right ventricular diastolic function in children with pulmonary regurgitation after repair of tetralogy of Fallot: volumetric evaluation by magnetic resonance velocity mapping. $7 \mathrm{Am}$ Coll Cardiol 1996;28:1827-35.

9 Jones EL, Conti CR, Neill CA, et al. Long-term evaluation of tetralogy patients with pulmonary valvular insufficiency resulting from outflow-patch correction across the pulmonic annulus. Circulation 1973;48(suppl 1):III-11-18.

20 Carvalho JS, Shinebourne EA, Busst C, et al. Exercise capacity after complete repair of tetralogy of Fallot: deleterious effects of residual pulmonary regurgitation. Br Heart f 1992;67:470-3.

21 Lange PE, Onnasch D, Bernhard A, et al. Left and right ventricular adaptation to right ventricular overload before and after surgical repair of tetralogy of Fallot. Am f Cardiol 1982;50:786-94

22 Ilbawi MN, Idriss FS, DeLeon SY, et al. Factors that exaggerate the deleterious effects of pulmonary insufficiency on the right ventricle after tetralogy repair. Surgical implications. $\mathcal{F}$ Thorac Cardiovasc Surg 1987;93:36-44.

23 Larrazet F, Pellerin D, Fournier C, et al. Right and left isovolumic ventricular relaxation time intervals compared by means of single-pulsed Doppler method. $f \mathrm{Am}$ Soc Echocardiogr 1997;10:699-706. 